\title{
Wear Performance of Hardened 1.2333 Cold Work Tool Steel by Plasma Electrolysis
}

\begin{abstract}
A. ÖZEL ${ }^{a}$ AND L.C. KUMRUOGLU ${ }^{a, b, *}$
${ }^{a}$ University of Sakarya, Engineering Faculty, Metallurgy and Materials Department, Sakarya, Turkey

${ }^{b}$ University of Cumhuriyet, Engineering Faculty, Metallurgy and Materials Department, Sivas, Turkey

Plasma electrolysis is an electrolytic-chemical-thermal technique that can be used for local hardening of the different type of steels. The feasibility of hardening the 1.2333 cold work tool steel by applying a single-stage-local surface treatment, which combines the methods of plasma electrolysis, is discussed. The effects of treatment durations of plasma electrolytic hardening on the surface microstructural, mechanical, and tribological characteristics of 1.2333 cold work steel substrates are studied. The major advantage of the plasma electrolytic hardening is shown to be hardened layer (maximum $900 \mathrm{Hv}$ - minimum $500 \mathrm{Hv}$ ) of the substrates consisting of martensitic phase in very short treatment durations, approximately $7 \mathrm{~mm}$ thick $/ 0.5 \mathrm{~min}$. Reciprocating-sliding friction and wear tests against an alumina ball counter face have shown that the application of a plasma electrolysis promotes a change in wear mechanism of the friction pair from relatively severe adhesion-abrasion to mild deformation. This results in simultaneous reduction of the volumetric wear rate from $0.18-0.2 \mathrm{~mm}^{3}$ to $0.04 \mathrm{~mm}^{3}$.
\end{abstract}

DOI: 10.12693 /APhysPolA.125.304

PACS: 81.40.Cd, 81.40.Ef, 52.50.-b, 52.77.-j

\section{Introduction}

The plasma electrolysis (PE) for heating and quenching of specimen surfaces has been known for 50 years. The application field of PE, state of the hardened surface, and results of industrial tests of parts are given in Table I. This technology is unique due to its ability to change the properties of surfaces. In plasma electrolysis the electric energy is usually transferred from a metallic anode to the specimen itself through the electrolyte and plasma layers. The plasma layer is formed from the electrolyte material in the gap between the liquid electrode and the conductive specimen surface [1-4]. This plasma heats the surface of specimen in short durations. PE is promising technology as an alternative to the laser and induction heating. 1.2333 is cast tool steel that offers advantageous characteristics of the high alloy material grades though it has low alloy percentage. Owing to its low carbon $(6 \%)$ content the material has both a very high toughness and high hardness numbers and has much better threshold temperatures and toughness. 1.2333 is suitable for the hardening via thermomechanic process in terms of heating and rapid quenching. In this study the PE process was performed to harden the 1.2333 steel and to improve the wear performance under reciprocating testing against alumina and steel balls.

\section{Experimental works}

All samples made from 1.2333 cast tool steel with a diameter of $50 \mathrm{~mm}$ and thicknesses of $10 \mathrm{~mm}$ were rounded

*corresponding author; e-mail: lkumruoglu@sakarya.edu.tr
TABLE I

Discharge and cyclic variation of the parameters for PE of 1.2333 steel.

\begin{tabular}{c|c|c|c|c|c}
\hline \hline \multicolumn{2}{c|}{$\begin{array}{c}\text { Specimen } \\
\text { No. and code }\end{array}$} & $\begin{array}{c}\text { PE } \\
\text { duration }\end{array}$ & $\begin{array}{c}\text { Heating } \\
\text { voltage [V] }\end{array}$ & $\begin{array}{c}\text { Holding } \\
\text { voltage [V] }\end{array}$ & $\begin{array}{c}\text { Specimen } \\
\text { temperature }\end{array}$ \\
\hline 1 & $3 \mathrm{i} 3 \mathrm{plc}$ & $6 \mathrm{sn}$ & 320 & 250 & 165 \\
2 & $3 \mathrm{i} 3 \mathrm{p} 2 \mathrm{c}$ & $12 \mathrm{sn}$ & 320 & 250 & 305 \\
3 & $3 \mathrm{i} 3 \mathrm{p} 3 \mathrm{c}$ & $18 \mathrm{sn}$ & 320 & 250 & 420 \\
4 & $3 \mathrm{i} 3 \mathrm{p} 4 \mathrm{c}$ & $24 \mathrm{sn}$ & 320 & 250 & 670 \\
5 & $3 \mathrm{i} 3 \mathrm{p} 5 \mathrm{c}$ & $30 \mathrm{sn}$ & 320 & 250 & 950 \\
6 & $3 \mathrm{i} 3 \mathrm{p} 6 \mathrm{c}$ & $36 \mathrm{sn}$ & 320 & 250 & 1070 \\
7 & $1 \mathrm{i} 5 \mathrm{p} 6 \mathrm{c}$ & $36 \mathrm{sn}$ & 320 & 250 & 725 \\
8 & $2 \mathrm{i} 4 \mathrm{p} 6 \mathrm{c}$ & $36 \mathrm{sn}$ & 320 & 250 & 950
\end{tabular}

and polished. Temperature measurements have been performed using two K type thermocouples placed in a hole that was drilled from the surface to plasma side close to $2 \mathrm{~mm}$ in the center of the specimen. The process parameters and measured temperatures were given in Table I. The PE voltages for the heating and holding stages were $320-250 \mathrm{~V}$, the application durations were $3 \mathrm{~s}$ and $3 \mathrm{~s}$, respectively. Total treatment durations were from $6 \mathrm{~s}$ to $36 \mathrm{~s}$. For example, the specimen code " $3 \mathrm{i} 3 \mathrm{p} 4 \mathrm{c}$ " means is $3 \mathrm{~s} 320 \mathrm{~V}, 3 \mathrm{~s} 250 \mathrm{~V}$ for 4 times, totally $3.3 \times 4=24 \mathrm{~s}$ heating time. An aqueous solution was prepared with $15 \mathrm{wt} \% \mathrm{Na}_{2} \mathrm{CO}_{3}$. The conductivity was varied between $90 \mathrm{mS}$ and the $\mathrm{pH}$ was 10.5. The electrolyte temperature was varied between $25^{\circ} \mathrm{C}$. The plasma electrolysis device consisted of a power supply, aqueous solution tank made of stainless steel, circulation pump, manipulator, and metallic anode nozzle. The unit has a DC power supply; with $500 \mathrm{~V}-100$ A power capacity $[2,3]$. After the plasma heating and quenching, all samples were examined using Rockwell C and a Leica VHMT MOT Microhardness tester with a load of $100 \mathrm{~g}$ from the treated side (plasma surface) to the interface zone and thermocouple surface. To examine different hardened areas, sections of sam- 
ples were polished and etched gradually $10 \mathrm{~s}$ with $15 \%$ $\mathrm{HNO}_{3}$ solution in ethyl alcohol and subsequently studied in a Leica MZ7.5 Stereo Microscope. A JEOL JSM $6060 \mathrm{LV}$ scanning electron microscope (SEM) equipped with energy-dispersive spectroscopy (EDS) was used for microstructure characterization of the hardened samples. In addition, the phase components of the treated samples were analyzed by X-ray diffraction (XRD) with using of RIGAKU XRD D/MAX/2200. The wear tests were performed both on the original 1.2333 and on the PE-modified specimens to determine the optimum process parameters. All the wear tests were carried out under dry sliding conditions at room temperature using a ball-on-disc (CSM), reciprocating wear test machine. The counterpart was an $\mathrm{Al}_{2} \mathrm{O}_{3}$ ball according to ASTM G 99-95a. The tests were performed with a nominal load of $10 \mathrm{~N}$ and a sliding frequency of $4 \mathrm{~Hz}$ and $10 \mathrm{~mm}$ sliding distance for the total sliding distance of $180 \mathrm{~m}$. Wear test parameters and results were given in Table II.

TABLE II

Discharge and cyclic variation of the parameters for $\mathrm{PE}$ of 1.2333 steel.

\begin{tabular}{c|c|c|c|c}
\hline $\begin{array}{c}\text { Specimen } \\
\text { No. }\end{array}$ & $\begin{array}{c}\text { Wear loss } \\
{\left[\mathrm{mm}^{3}\right]}\end{array}$ & $\begin{array}{c}\text { Load } \\
{[\mathrm{N}]}\end{array}$ & $\begin{array}{c}\text { Distance } \\
{[\mathrm{m}]}\end{array}$ & $\begin{array}{c}\text { Counter } \\
\text { ball }\end{array}$ \\
\hline Untreated & 0.26 & 10 & 180 & $\mathrm{Al}_{2} \mathrm{O}_{3}$ \\
1 & $0.182-0.183$ & 10 & 180 & $\mathrm{Al}_{2} \mathrm{O}_{3}$ \\
2 & 0.182 & 10 & 180 & $\mathrm{Al}_{2} \mathrm{O}_{3}$ \\
3 & 0.09367 & 10 & 180 & $\mathrm{Al}_{2} \mathrm{O}_{3}$ \\
4 & 0.075 & 10 & 180 & $\mathrm{Al}_{2} \mathrm{O}_{3}$ \\
5 & $0.038-0.04$ & 10 & 180 & $\mathrm{Al}_{2} \mathrm{O}_{3}$ \\
6 & 0.045 & 10 & 180 & $\mathrm{Al}_{2} \mathrm{O}_{3}$
\end{tabular}

\section{Results}

The mechanical performance of specimens after PE hardening was evaluated by Brinell and micro hardness testing throughout the hardened layer. The results are given in Fig. 1 and Fig. 2 for each hardening parameters. At short durations such as $12 \mathrm{~s}$ even some slight increase was measured on the near surface of the treated layer; the hardness depth was $1000 \mu \mathrm{m}$ beneath of surface. The reason is probably because of low heating temperature during the discharging. In addition, the core of substrate cannot heat the austenite temperature for the essential carbon diffusion then desired phase change into martensite by quenching. SEM view proof that the specimen 5 has modified, the grain boundaries, carbide web, and martensite phases can be seen in Fig. 3. Also, for the specimen 6 , coarsening grains can be revealed. This situation may stem from the high austenization temperatures.

XRD measurements confirm the fact that the 1.2333 substrate was heated up to austenization temperature by the PE. The several iron-oxides and martensite (Fe) phases were formed on the surface (Fig. 4). These formations such as martensite and iron carbide lead to increase in surface micro hardness. The surface hardness of the

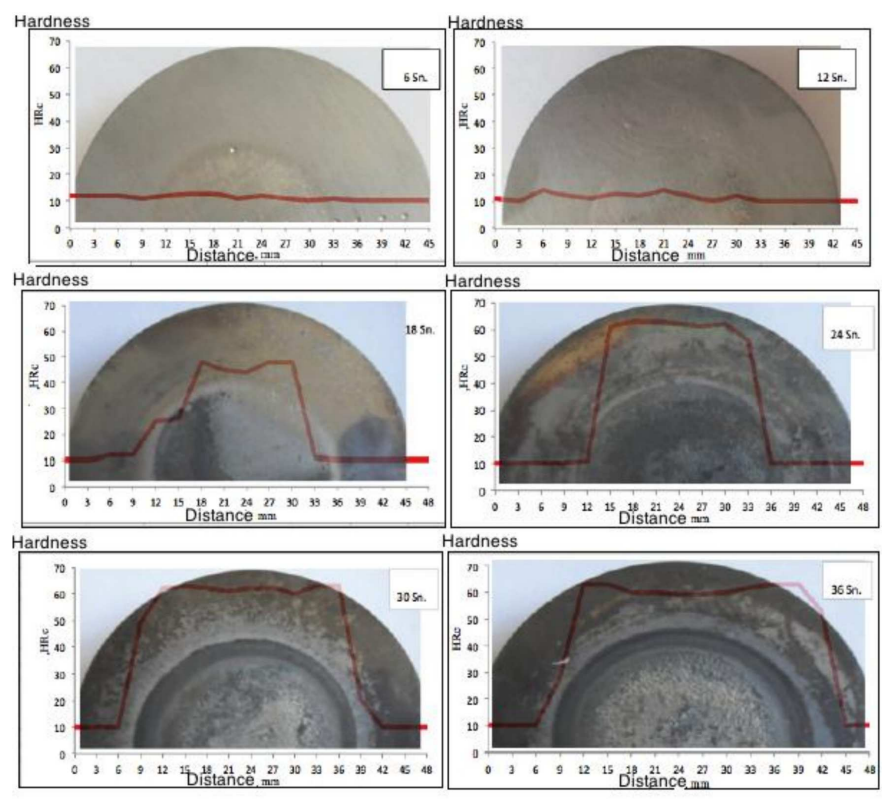

Fig. 1. Photographs of PE performed samples and the characteristic plasma spot.

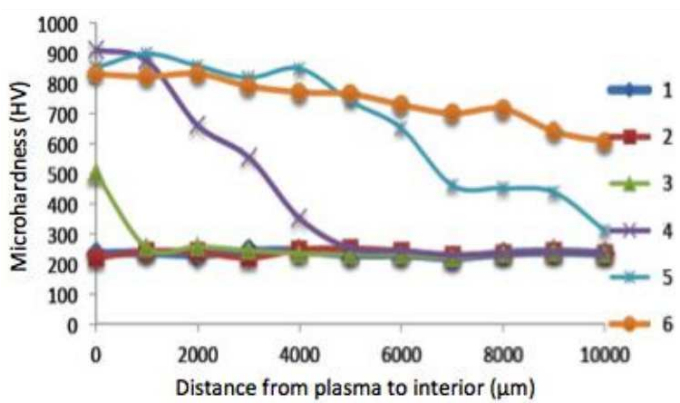

Fig. 2. Micro hardness depth of PE hardened specimens.

1.2333 steel increased from about $225 \mathrm{HV}_{(25)}$ to about 800-900 $\mathrm{HV}_{(25)}$ after PE (Fig. 2).

It is expected that the hardened hard zone may provide a better wear resistance due to its high hardness. Table II shows the variation of wear loss with at $10 \mathrm{~N}$ applied normal load and $180 \mathrm{~m}$ sliding distance for the treated spec-
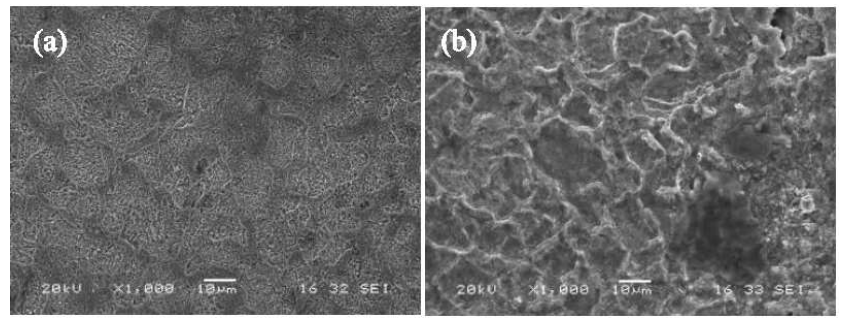

Fig. 3. SEM view of specimen 5 (a) and specimen $6(b)$. 


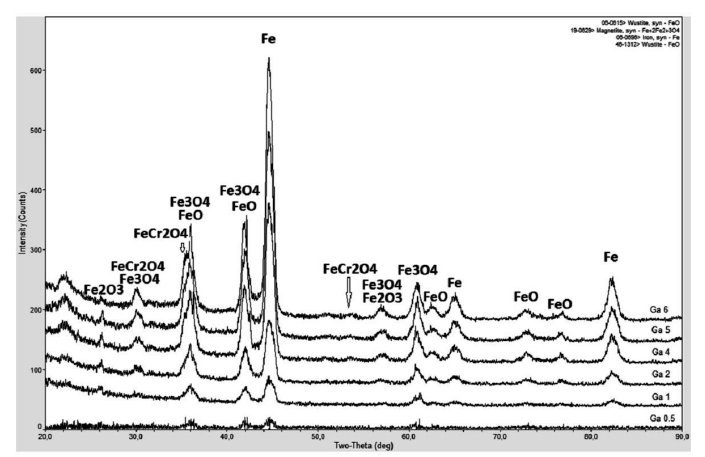

Fig. 4. XRD of specimen 6 and possible surface phases.

imens. It can be seen that the wear lost does not show a remarkable difference, for specimen 1 and 2 , but the wear resistance is much greater, compared to that of the untreated 1.2333 steel under the same load. Wear lost shows a remarkable decrease, after testing specimen 3 . The best wear resistant was achieved at the specimen 5 that was heated $30 \mathrm{~s}$ and subsequently quenched. But the specimen 6's wear resistance is lower than of the " 5 ", this decrease can be explained by the overheating and surface roughening. The surface roughness profile for all specimens was plotted in Fig. 5. It is very clear that increase of the process duration increases the surface roughness.

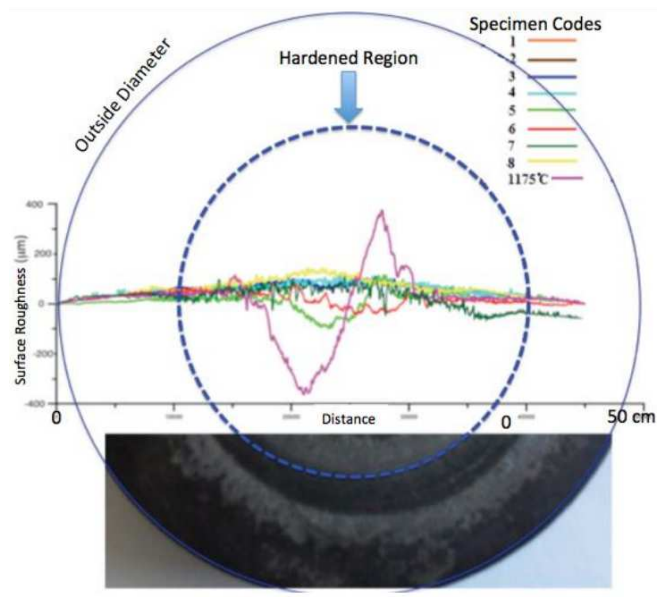

Fig. 5. Surface roughness and profile of all specimens.

Figure 6 shows the wear scars of the hardened (a) and untreated (b) specimens. The improved tribological performance of hardened further confirmed by comparing the worn surfaces of the specimens under dry friction conditions using SEM, OM images, EDS and weight analyses. It is observed that the wear track of the hardened steel becomes shallow and narrow and don't exhibits slightly wear damage. This demonstrates the PE process improves the wear resistance of hardened steel. On the other hand, SEM detected severe plastic deformation, abrasive scars and delamination from unhardened samples.
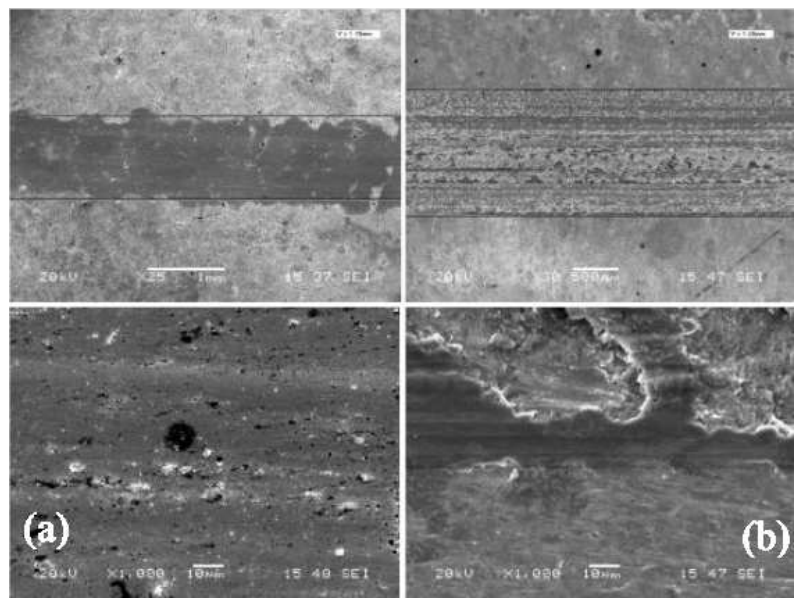

Fig. 6. SEM images of wear scars for plasma hardened (a) and untreated specimens (b).

\section{Conclusions}

The hardened layer, which is consisting of multi-phase combinations of including mixtures of $(\mathrm{Fe})_{2-3} \mathrm{O}_{3-4}$, austenite, martensite, $(\mathrm{Fe}){ }_{x} \mathrm{C}$ improved the wear resistance of 1.2333 cold work tool steel in the linearly reciprocating ball-on-plate sliding condition under $10 \mathrm{~N}$ load. The wear mechanism was mainly affected by abrasive particles fractured from hardened layer and adhesion at $10 \mathrm{~N}$ load. The best wear resistance performance was achieved at the specimen coded " $3 \mathrm{i} 3 \mathrm{p} 5 \mathrm{c}$ ".

\section{References}

[1] Yu.N. Tyurin, A.D. Pogrebnjak, Surf. Coat. Technol. 142-144, 293 (2001).

[2] L. Cenk Kumruoglu, D. Alexander Becerik, A. Ozel, A. Mimaroglu, Mater. Manufact. Proc. 24, 781 (2009).

[3] L.C. Kumruoglu, A. Ozel, Acta Phys. Pol. A $\mathbf{1 2 3}$, 404 (2013).

[4] A.L. Yerokhin, X. Nie, A. Leyland, A. Matthews, S.J. Dowey, Surf. Coat. Technol. 122, 73 (1999). 